\title{
CORRECTIONS
}

\section{Author Correction: Sodium channelopathies in neurodevelopmental disorders}

Miriam H. Meisler(D, Sophie F. Hill(1) and Wenxi Yu(D)

Correction to: Nature Reviews Neuroscience https://doi.org/10.1038/s41583-020-00418-4, published online 02 February 2021.

In the original version of this article, the title of Figure 3 was incorrect. The gene name SCN3A should have been written as SCN8A. This error has now been corrected in the HTML and PDF versions of the article.

https://doi.org/10.1038/s41583-021-00449-5 I Published online 8 March 2021

(c) Springer Nature Limited 2021

\section{Publisher Correction: Reverse engineering Lewy bodies: how far have we come and how far can we go?}

Mohamed Bilal Fares, Somanath Jagannath and Hilal A. Lashuel D

Correction to: Nature Reviews Neuroscience https://doi.org/10.1038/s41583-020-00416-6, published online 11 January 2021.

In the originally published article, two of the headings appeared incorrectly. 'Again LB training' should have read 'De novo LB formation' and 'The model is again LB formation' should have read 'A model for de novo LB formation'. These headings have been corrected in the HTML and PDF versions of the manuscript.

https://doi.org/10.1038/s41583-021-00447-7 I Published online 2 March 2021

(๑) Springer Nature Limited 2021 